\title{
Shear degradation model of HPAM solutions for the design of regulator valves in polymer flooding EOR
}

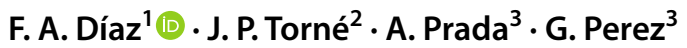 \\ Received: 18 December 2019 / Accepted: 5 May 2020 / Published online: 13 May 2020 \\ (c) The Author(s) 2020
}

\begin{abstract}
Polymer flooding for enhanced oil recovery is increasingly in demand in countries such as Colombia, where ECOPETROL has taken major steps in applying this technique to revitalize mature oil fields. The purpose of injecting polymer into reservoirs is to increase the viscosity of the aqueous phase to enhance the mobility ratio. Several aspects can affect and weaken the performance of a polymer flooding operation, however, most of them can be controlled. One of the most important factors is the degradation of the polymer by shear, which causes a reduction in the aqueous phase viscosity. This study was based on work related to the degradation of HPAM solutions induced by the use of regulator valves to control flow and pressure in multiple zones in the same well or multiple wells connected to the same pump. Several tests were completed in a facility designed and prepared to perform regulator valves testing. The results obtained during the initial phase of the testing were compared to computational fluid dynamics simulations, obtaining a shear degradation model which can be used to optimize the design of regulator valves or any other flow control device.
\end{abstract}

Keywords Enhanced oil recovery · Computational fluid dynamics · Increasing oil production · Revitalize mature oil fields · HPAM degradation correlation - HPAM rheological model

\section{Introduction}

The tertiary techniques used to extract crude oil and gas from a mature oil field are known as enhanced oil recovery (EOR). These techniques are thermal treatment, gas injection and chemical injection. Polymer flooding is the most common chemical EOR method implemented at field scale as a strategy, increasing oil production and reducing water cut (Perez et al. 2017).

A polymer flooding process consists in dissolving polymer in injection water to increase its viscosity and inject the latter into an oil-bearing formation over an extended period of time to enhance oil recovery. When about $30-50 \%$ of the reservoir pore volume in the project area has been injected, the addition of polymer stops and drive water is pumped into

\footnotetext{
F. A. Díaz

fabiandiazmateus@hotmail.com

AC Ingenieria Virtual, Bucaramanga, Colombia

2 SPE, Bogotá, Colombia

3 ECOPETROL S.A., Bogotá, Colombia
}

the injection well to drive the polymer slug and the oil bank in front of it toward the production wells (Zerkalov 2015).

The effectiveness of a water/polymer flooding operation is strongly influenced by a parameter known as the mobility ratio $(M)$.

$M=k_{w} \mu_{o} / k_{o} \mu_{w}$

where $k_{w}$ is the relative permeability of water in the waterflooded zone, $k_{o}$ is the relative permeability of oil in the oil-saturated zone, $\mu_{o}$ is the viscosity of the oil and $\mu_{w}$ is the viscosity of water. Values for the mobility ratio lower than 1 favor higher oil recovery with a uniform displacement of oil (Rellegadla et al. 2017). It can be seen on Eq. 1 that increasing $\mu_{w}$ will decrease $M$ and therefore improve oil recovery which can be obtained by injecting polymer solutions into the reservoir.

Polymers used in EOR are one of two types, synthetic or biological. A synthetic polymer called partially hydrolyzed polyacrylamide, or HPAM, and its derivatives are the most employed in EOR operations due to its lower cost (Sheng 2013). However, HPAM is susceptible to chemical, thermal, photolytic, biological and mechanical (shear) degradation (Xiong et al. 2018) which can significantly reduce

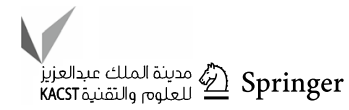


the viscosity of the solution and the effectiveness of the EOR operation. Chemical degradation is caused by the oxidation of $\mathrm{Fe}^{2+}$ with oxygen. It can be significant when HPAM solutions are transported long distances in pipelines if proper precautions are not taken into account such as the use of deoxygenated water and oxygen scavengers (Jouenne et al. 2014). Shear degradation occurs when the solution is forced to pass through small openings or restrictions which are normally used for pressure and flow control. High shear and elongational rates can be found at the entrance of small openings, causing the polymer chain to break mostly near the mid-point (Perkins et al. 1997, Al Hashmi et al. 2013).

In polymer flooding operations, a control valve is generally installed on the wellhead of each well to regulate the injection pressure and flow rate (Husveg et al. 2019). However, it can be desirable to regulate the flow at different depths in the same well. Regulator valves are essential in polymer flooding operations in order to obtain an optimal vertical sweep efficiency. Regulator valves are installed in injection wells in side pocket mandrels at different depths inside the well. Mandrels are usually installed in each layer or zone in the reservoir with different permeability or mobility ratios (Seright 2017). As each zone may have different properties and pressures, regulators valves inside a single well may be required to control different flow/pressure conditions. Wang et al. (2008), based on their experience with polymer flooding at the Daqing oil field, assured that separate layer injection was found to improve flow profiles, reservoir sweep efficiency and injection rates and it can reduce the water cut in production wells.

Polymer flooding operations in La Cira and Casabe (Colombia) inject about 200-600 barrels per day (BPD) of HPAM solutions with a required pressure drop about 400-1000 psi per regulator valve (Castro et al. 2010). About 1000-2500 BPD of HPAM were injected per well in the Yarigui-Cantagallo field (Colombia) (Castro-García et al. 2016). Recently, operations in La Cira planned to increase the injection of polymer to multiple zones with pressure difference between reservoir and injection from 1000 up to 2500 psi.

In the literature can be found mechanical degradation models of HPAM based on different approaches. Degradation has been studied mostly in porous media as an attempt to replicate the behavior of the flow in a reservoir, but it has also been studied by flowing through tubes, coils, nozzles and holes of different diameter. Strickland et al. (1978) in an attempt to convert a waterflood project at Yellow Creek Field into a polymer flood studied the degradation of HPAM passing through a $3 / 8^{\prime \prime}$ diameter tubing and a sand pack. Results from these investigators show that as the flow rate increased, the degradation increased as well in the tubing and the sand pack. A degradation model was not presented. Stavland et al. (2010) presented an apparent viscosity model for HPAM solutions where degradation is considered as a mechanical shear thinning exponent and a time constant. Those parameters were measured in core flood experiments with cores of 1.5 inches diameter and $7 \mathrm{~cm}$ long. Bulk viscosity was calculated with the Carreau model. These investigators affirmed that the bulk viscosity is different to the apparent viscosity while flowing through the porous media and that their rheological model effectively predicted the experimental results.

Jouenne et al. (2014) developed an investigation on the degradation of HPAM during transport in pipelines. A large scale facility was constructed for this work with four pipe loops up to $7 \mathrm{~km}$ long. They correlated degradation with flow velocity and recommend using a velocity lower than $3.7 \mathrm{~m} / \mathrm{s}$ to avoid degradation of HPAM. Bouts and Rijkeboer (2014) carried out an investigation on the degradation of HPAM in screens with outflow control devices (OCD). This OCD had nozzles of different diameters to investigate the degradation while HPAM was injected through them. These investigators recommended using nozzles of at least $4 \mathrm{~mm}$ in diameter in order to avoid degradation. Jouenne et al. (2017) made an investigation on the degradation of HPAM in capillaries, blenders and porous media. They concluded that in capillaries degradation depends on the velocity rather than in the shear rate. Additionally, they found that passing through $6 \mathrm{~mm}$ of porous media is sufficient to reach a steady state of degradation. Gomez et al. (2018) developed an investigation on the degradation of HPAM in a pilot scale facility where HPAM solutions passed through holes of 2-9 $\mathrm{mm}$ diameter in flows of 25-700 BPD. They plotted a response surface of flow versus hole diameter which shows that there should be zero degradation in holes over $5 \mathrm{~mm}$ in diameter. Husveg et al. (2019) presented the design of a control valve to be installed at the wellhead for polymer flooding. These investigators claim that with the use of evenly spaced contractions and multiple flow channels it is possible to reduce degradation by about $10 \%$ at 40 bar pressure drops.

An optimal regulator valve for polymer flooding should be able to control flow and pressure drops without degrading the polymer. At high pressure drops this can be very difficult as common regulator valves employ variable or fixed restrictions that cause high shear in the flow. Water regulator valves are not designed to properly control the flow of polymer solutions and they degrade it at high flow rates or high pressure drops due to high shear. The amount of degradation caused by the well equipment has to be compensated for with more polymer to attain the designed mobility ratio which can represent a significant loss of money.

In this work, a 1.5 inch regulator valve was designed to control the flow of HPAM solutions at high pressure drops with low degradation to be used in side pocket mandrels at different depths for polymer or water flooding. The valve was designed in a way that internals could be easily replaced in 
order to evaluate the degradation at different conditions. Two types of internals were designed. The first type was a design of reduction-expansions installed in tandem. Four different diameters were used for the reductions. The second type was a screw-like design. The valve was tested in a facility constructed for regulator valves testing with flows between 200 and $600 \mathrm{BPD}$, pressure drops between 50 and $1700 \mathrm{psi}$ and HPAM solution concentrations of 500, 700 and $1000 \mathrm{ppm}$. Viscosity of the solutions was measured before and after passing through the valve and degradation was calculated. Computational fluid dynamics (CFD) simulations were performed for every test in order to correlate the degradation values obtained experimentally with flow related parameters and to develop degradation models. Results showed that it is possible to control the flow of HPAM solutions at high flow rates and high pressures obtaining a percentage of degradation up to $3 \%$, with an optimal design of the regulator valve internals.

\section{Regulator valve for polymer injection}

A regulator valve to control water and polymer flow was designed and constructed. The outside diameter (OD) was 1.5 inch, and the length was about $681 \mathrm{~mm}$, a RK retrievable latch permitted the installation with wireline in side pocket mandrels and it is presented in Fig. 1. This valve included specially modified sealing elements to control the additional pressure difference, special seat for multiple inner regulator sections up to 20 tandem, expansion exit chamber to reduce flow velocity and minimize polymer degradation when exiting the valve while allowing the installation of a back-flow control shear pin. Two types of internals were designed and constructed, the first type is a series of reductions of 4.5, 5, 5.5 and $6 \mathrm{~mm}$ in diameter followed by expansions of $9 \mathrm{~mm}$ in diameter, these internals can be seen in Fig. 2. Reductions used in the tests had the same diameter, reductions of different diameter were not combined. For the second type, the reductions and expansions are removed from the central cylindrical piece and a screwlike piece is inserted instead which creates two spiral channels inside for the flow. Two screws were tested, one with a $3 \mathrm{~mm}$ wide $-4.5 \mathrm{~mm}$ depth channel that makes 28 loops and a $4 \mathrm{~mm}$ wide $-4.5 \mathrm{~mm}$ depth channel that makes 24 loops.

The series of reductions-expansions allowed the management of pressure drop in small increments while controlling the flowrate based on the orifice selected with flow stabilization. The principle is alike a damper valve, this design is in patent process with ECOPETROL. The screw piece assembly was designed to take advantage of the volume available to perform a spiral movement in the flow that should create a smooth pressure drop and low polymer degradation. The principle is similar to that used by Husveg et al. (2019), these researchers used long channels in spiral to create a smooth pressure drop while maintaining a reasonable size of the wellhead control valve.

\section{Experimental work}

The valve was tested in a facility provided by an external company. It consisted in a test loop with a $1 \mathrm{~m}^{3}$ plastic tank for the fresh HPAM solution and another for the degraded one. A low shear 3 stage positive displacement pump was employed to drive the polymer through a modified mandrel where the valve was installed (see Fig. 3). Samples of HPAM were taken before and after the mandrel to avoid taking into account any possible degradation caused by fittings or the pump. A percentage of degradation was calculated with Eq. 2. The pump was set at 3000 psi discharge pressure for every test.

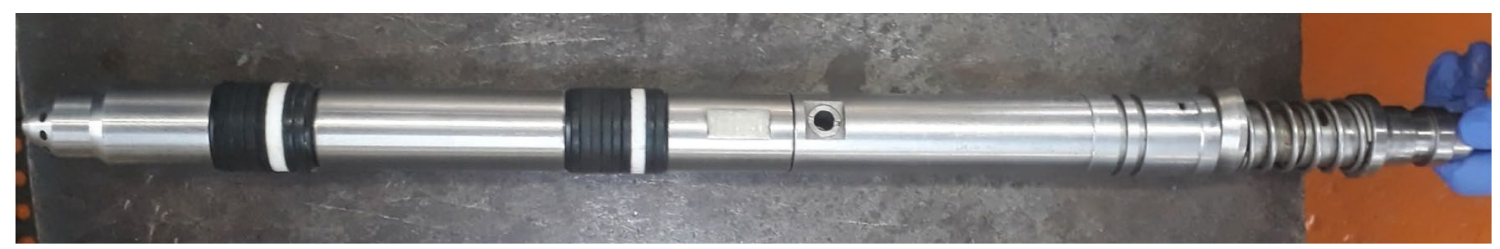

Fig. 1 The regulator valve for polymer injection

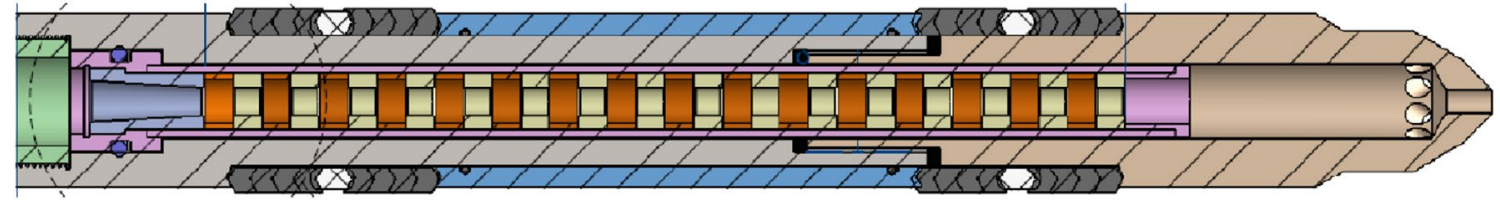

Fig. 2 CAD image of the $6 \mathrm{~mm}$ diameter reductions $-9 \mathrm{~mm}$ diameter expansions in the regulator valve 
Fig. 3 Facility for regulator valves testing

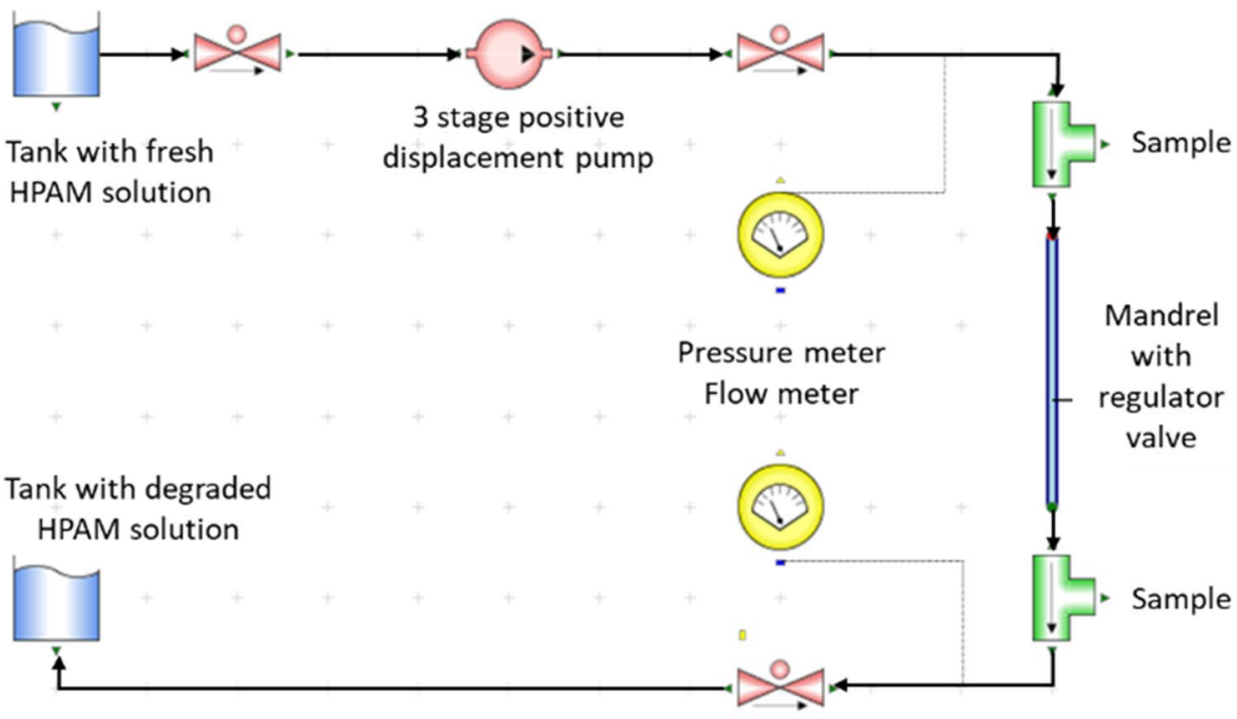

$\%$ Deg $=\frac{\mu_{\text {non }}-\mu_{\text {deg }}}{\mu_{\text {non }}-\mu_{\text {water }}} \times 100$

where $\mu_{o}$ Viscosity of non-degraded solution $[\mathrm{kg} / \mathrm{ms}], \mu_{\mathrm{deg}}$ Viscosity of degraded solution $[\mathrm{kg} / \mathrm{ms}], \mu_{\text {water }}$ Viscosity of water $[\mathrm{kg} / \mathrm{ms}]$.

In this work, the degradation of the HPAM solutions was provided as a percentage reduction in viscosity, calculated according to Eq. 2. The same procedure was used by other authors such as Gomez et al. (2018) and Husveg et al. (2019). Viscosity was measured at a shear rate of $7 \mathrm{~s}^{-1}$ and a temperature of $30{ }^{\circ} \mathrm{C}$.

Three HPAM solution concentrations were employed in every test; 500 ppm, 700 ppm and 1000 ppm. The viscosity of the three solutions was measured in the laboratory at shear rates between 4 and $500 \mathrm{~s}^{-1}$ and the Carreau-Yasuda model (Yasuda, 1979), presented in Eq. 3, was found to fit best the experimental data. Carreau-Yasuda model parameters for the three solutions are on Table 1. The Carreau-Yasuda model allowed the prediction of a sheardependent viscosity in the CFD simulations.

$\frac{\mu-\mu_{\infty}}{\mu_{0}-\mu_{\infty}}=\left[1+(\gamma \lambda)^{a}\right]^{\frac{n-1}{a}}$

where $a$ Carreau parameter, $\lambda$ time constant [s], $\mu_{0}$ zeroshear-rate viscosity $[\mathrm{kg} / \mathrm{ms}], \mu_{\infty}$ infinite-shear-rate viscosity [kg/ms], $n$ Pseudo-plasticity index, $\mu$ shear-dependent viscosity $[\mathrm{kg} / \mathrm{ms}]$.

\section{Valve testing results}

Pressure drop and percentage of degradation of HPAM obtained in the tests of the valve with the EOR-500 solution are presented in Figs. 4 and 5 respectively. $4.5-9 \mathrm{~mm}$, 5-9 $\mathrm{mm}, 5.5-9 \mathrm{~mm}$ and 6-9 $\mathrm{mm}$ correspond to the diameters of the reduction-expansions. Screw $3 \mathrm{~mm}-28 \mathrm{~L}$ and Screw $4 \mathrm{~mm}-24 \mathrm{~L}$ correspond to the spiral channel wide and number of loops, the same notation was used on Fig. 10. Results obtained with EOR-700 and EOR-1000 are similar and show the same increasing tendency that is presented on Figs. 4 and 5 , demonstrating excellent repeatability and consistency. The complete set of experimental results is presented in Table 3 of "Appendix".

\section{CFD simulations}

CFD simulations were performed for every test in order to correlate the percentage of degradation obtained in the experimental tests with flow parameters and develop degradation models. In order to develop a degradation model that can be used to design any control device, those flow
Table 1 Carreau-Yasuda model parameters for the three solutions

\begin{tabular}{lclrrrr}
\hline HPAM solution & \multicolumn{1}{l}{$\begin{array}{l}\text { HPAM concen- } \\
\text { tration (PPM) }\end{array}$} & $n$ & \multicolumn{1}{l}{$a$} & \multicolumn{1}{l}{$\mu_{0}$} & \multicolumn{1}{l}{$\lambda$} \\
\hline EOR-500 & 500 & 0.44980 & 8.13836 & 64.70789 & 0.04510 & 0.42812 \\
EOR-700 & 700 & 0.38030 & 11.07136 & 117.14461 & 0.06518 & 0.43804 \\
EOR-1000 & 1000 & 0.32140 & 17.88069 & 176.89382 & 0.13214 & 0.63766 \\
\hline
\end{tabular}




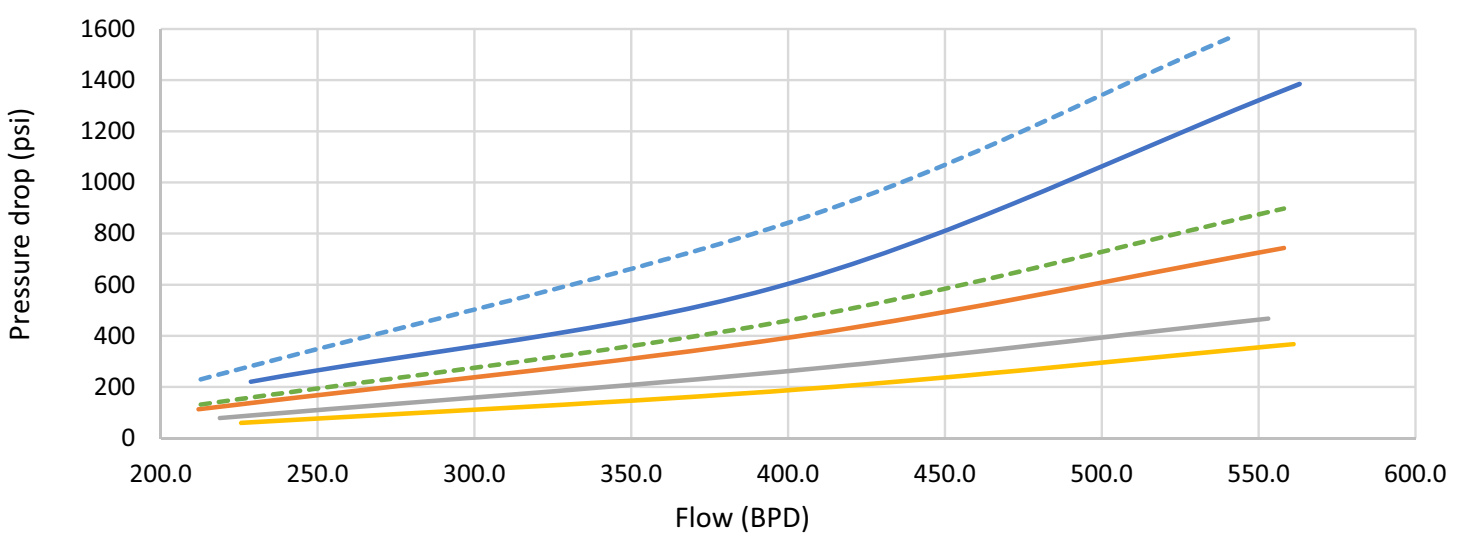

$-4.5 \mathrm{~mm}-9 \mathrm{~mm} \longrightarrow 5 \mathrm{~mm}-9 \mathrm{~mm} \longrightarrow 5.5 \mathrm{~mm}-9 \mathrm{~mm} \longrightarrow 6 \mathrm{~mm}-9 \mathrm{~mm}=-\cdots$. Screw $3 \mathrm{~mm}-28 \mathrm{~L}=-\cdots$ Screw $4 \mathrm{~mm}-24 \mathrm{~L}$

Fig. 4 Pressure drop obtained in the tests of the valve with EOR-500 solution

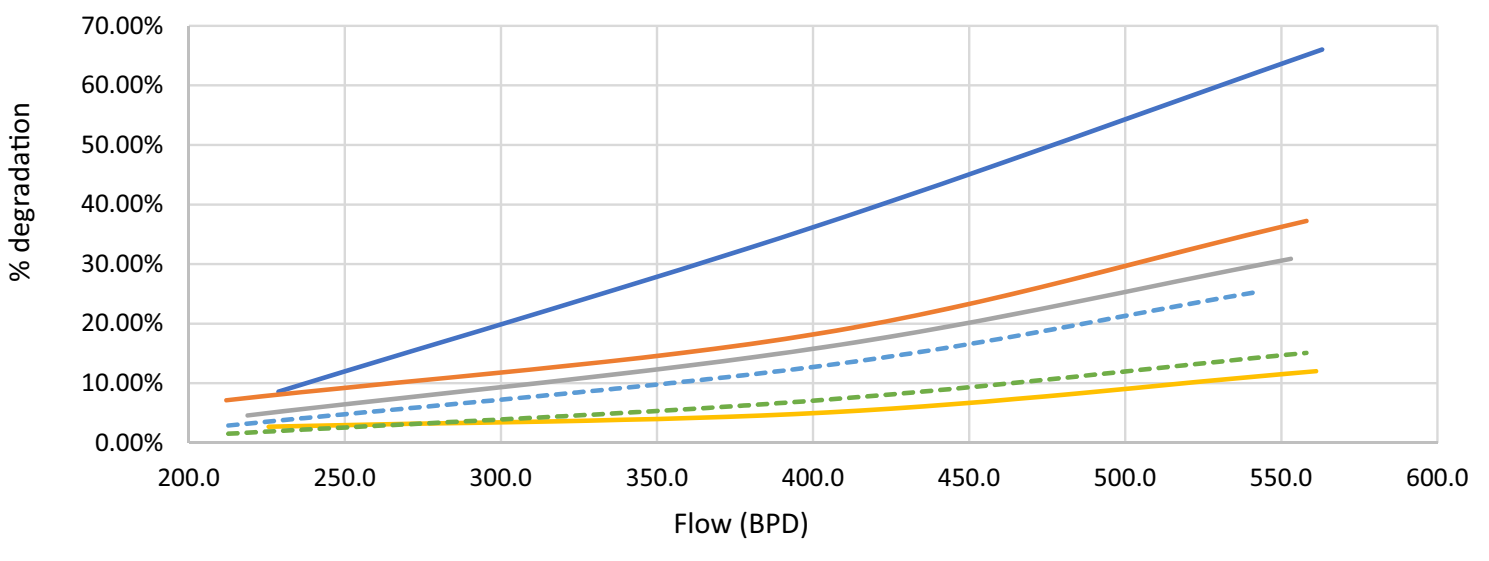

Fig. 5 Percentage of degradation of HPAM obtained in the tests of the valve with EOR-500 solution

Table 2 Parameters employed in the CFD simulations

\begin{tabular}{ll}
\hline $\begin{array}{l}\text { Solver } \\
\text { Turbulence model }\end{array}$ & $\begin{array}{l}\text { Pressure based, steady state } \\
\text { Non-Newtonian, Realizable } k-e \text {, scalable } \\
\text { wall functions }\end{array}$ \\
Walls & No slip, Roughness height: $1 \mathrm{e}-5 \mathrm{~m}$ \\
Solution methods & SIMPLEC, Second order discretization \\
Mesh & Aprox. $1,000,000$ cells, $y^{+}<300$ in all cases \\
\hline
\end{tabular}

parameters must be independent of the size and type of restriction and represent the forces exerted on the fluid by the valve. Only the geometry of the flow passing through the valve was simulated. The software employed in the simulations was ANSYS FLUENT, as the Carreau-Yasuda rheological model is not present in this software by default, it was programmed in $\mathrm{C}$ language as a User Defined Function
(UDF) and compiled. Parameters employed in the CFD simulations are presented in Table 2.

The pressure drop obtained in the simulations was compared with the experimental results in order to validate the CFD models. A percentage of deviation of the simulation results is calculated with Eq. 3.

$\%$ Deviation $=\left|\frac{\Delta P_{\text {Experimental }}-\Delta P_{\text {Simulation }}}{\Delta P_{\text {Experimental }}}\right| \times 100$

Figure 6 shows the meshing of the CAD geometry of the flow passing through the $4.5-9 \mathrm{~mm}$ internals. Figure 7 presents the wall shear stress obtained in the simulation of the geometry of Fig. 6 with a flow of 564 BPD of HPAM with a concentration of $1000 \mathrm{ppm}$. It shows how the maximum value in the wall shear stress is found at the entrance of each reduction. 


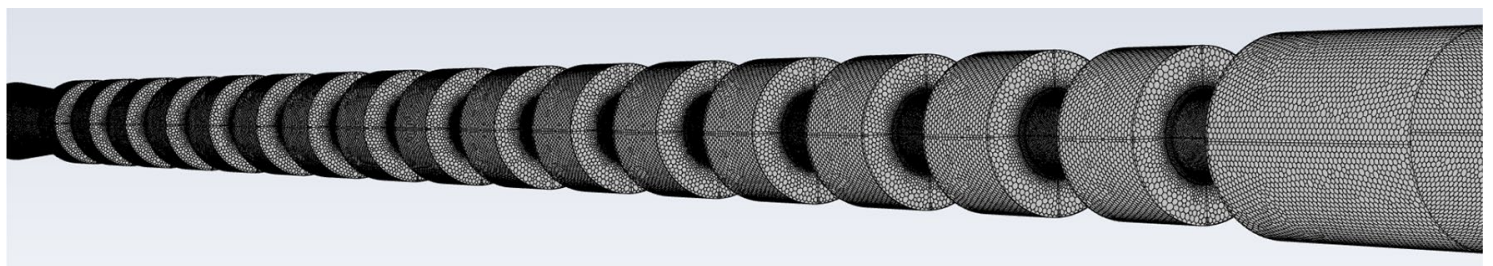

Fig. 6 Meshed CAD of the 4.5-9 mm internals geometry

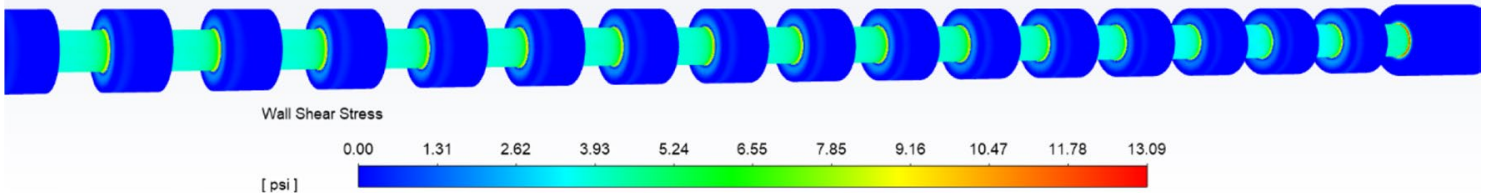

Fig. 7 Wall shear stress (psi) obtained in the CFD simulation of 4.5-9 mm internals with flow of 564BPD and 1000 ppm of HPAM concentration

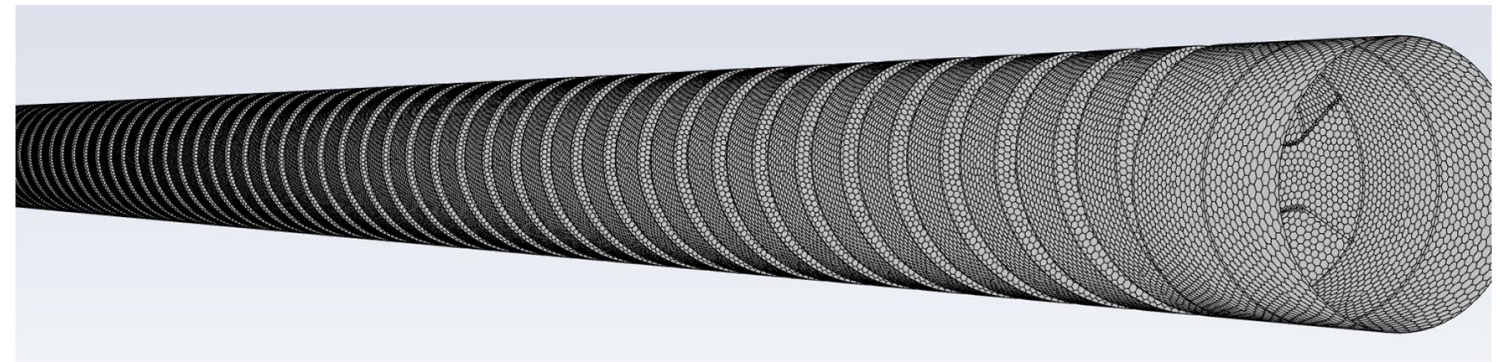

Fig. 8 Meshed CAD of the $3 \mathrm{~mm}$ wide $-4.5 \mathrm{~mm}$ depth channel-28 loop screw geometry

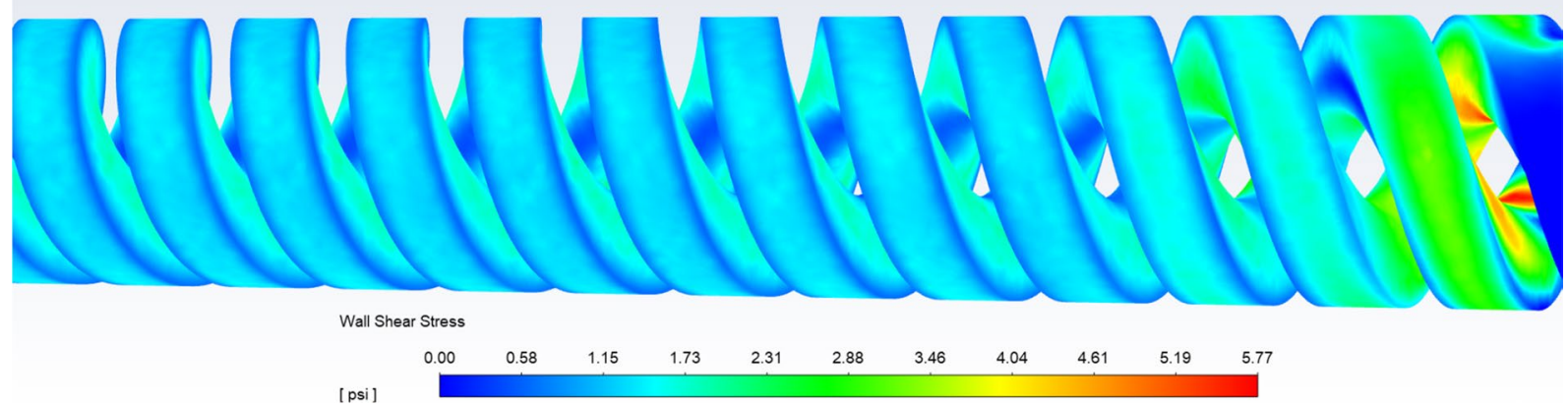

Fig. 9 Wall shear stress (psi) obtained in the CFD simulation of $3 \mathrm{~mm}$ wide- $4.5 \mathrm{~mm}$ depth channel-28 loop screw with flow of 563 BPD and 1000 ppm of HPAM concentration

Figure 8 shows the meshing of the CAD geometry of the flow passing through the $3 \mathrm{~mm}$ wide- 4.5 depth-28 loop screw. Figure 9 presents the wall shear stress obtained in the simulation of the geometry of Fig. 8 with a flow of 564 BPD of HPAM with a concentration of $1000 \mathrm{ppm}$. It shows how the maximum value in the wall shear stress is found at the entrance of the screw.
Figure 10 compares the results of the CFD simulations with the experimental results. An average percentage of deviation of $4.5 \%$ was obtained and was considered a satisfactory agreement. The complete set of results is presented in Table 3 of "Appendix".

A degradation model independent of the size and type of restriction was desirable. Such degradation model was 


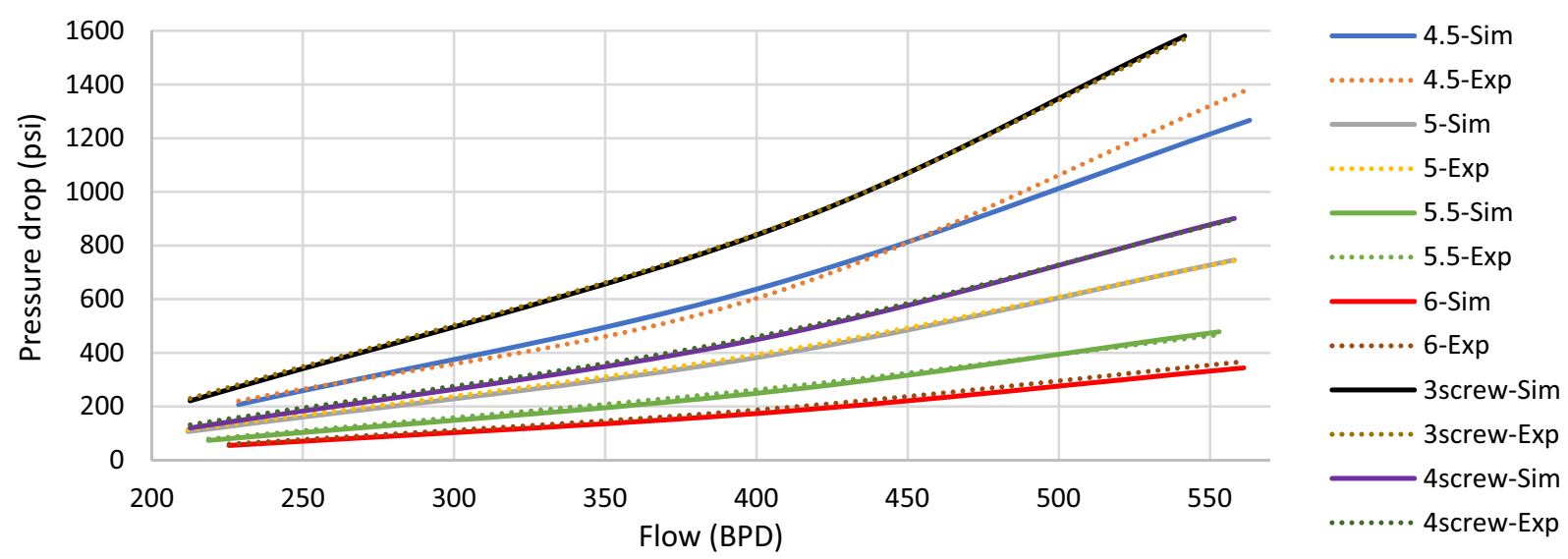

Fig. 10 Comparison between the pressure drop obtained in the CFD simulations (Sim) and the pressure drop obtained experimentally (Exp)

obtained by comparing the experimental degradation values with flow related parameters calculated in the CFD simulations. Three parameters that depend only on flow variables were evaluated in the CFD simulations and compared to the degradation found experimentally in search of the best regression coefficients. Those parameters were:

- Maximum wall shear stress

- Average wall shear stress

- Mass average strain rate

All the correlations were forced to pass through the origin (0 pressure drop, 0 degradation). Wall shear stress and strain rate are calculated with Eqs. 6 and 7 respectively. Figure 11 presents the correlations found between the selected parameters and the percentage of degradation for the three HPAM solutions. Regression coefficients $\left(\mathrm{R}^{2}\right)$ indicate that the average wall shear stress was the best parameter to evaluate the percentage of degradation of the HPAM solutions with an average value of 0.97 ( 1 being a perfect fit). The effect of the HPAM concentration was analyzed in Fig. 12. The percentage of degradation obtained in all the experiments was compared to its corresponding average wall shear stress obtained in the CFD simulations and a similar behavior was found in the three HPAM concentrations.

$$
\begin{aligned}
& \overline{\bar{D}}=\left(\frac{\partial u_{i}}{\partial x_{j}}+\frac{\partial u_{j}}{\partial x_{i}}\right) \\
& \tau_{w}=\mu|\overline{\bar{D}}|_{x=0} \\
& \gamma=\sqrt{0.5 \overline{\bar{D}}: \overline{\bar{D}}}
\end{aligned}
$$

where $\tau_{w}$ wall shear stress [psi], $u$ velocity [m/s], $x$ distance [m], $\mu$ shear-dependent viscosity $[\mathrm{kg} / \mathrm{ms}], \overline{\bar{D}}$ rate of deformation tensor, $\gamma$ strain rate $\left[\mathrm{s}^{-1}\right]$.

\section{Analysis of the experimental and simulation results}

The valve was designed to regulate the flow of HPAM solutions at a flow rate of 200-600 BPD and a pressure drop of 500-800 psi with zero degradation. With a 1.5 inch OD, the valve is to be installed in mandrels to control the flow at different depths in the well. The small size of the valve provides a very limited space to manage the flow of polymer without degrading it. A series of short reductions and expansions installed in tandem were designed to provide a smooth pressure drop throughout the whole extent of the valve. At a pressure drop of $580 \mathrm{psi}$, the degradation found in all the experiments was about $30 \%$.

The screw was designed to take advantage of more of the volume available within the valve. The transversal area of the $3 \mathrm{~mm}$ wide $-4.5 \mathrm{~mm}$ depth channel is $12.35 \mathrm{~mm}^{2}$ and for the $4 \mathrm{~mm}$ wide- $4.5 \mathrm{~mm}$ depth channel is $15.85 \mathrm{~mm}^{2}$, which corresponds with a $4 \mathrm{~mm}$ and $4.5 \mathrm{~mm}$ diameter reduction respectively. Nonetheless, the flow is divided by half since the screw creates dual spiral channels. These spiral channels produce a smooth pressure drop while maintaining a low wall shear stress since the flow is divided half. The spirals also reduce the size of the valve because what could be a $1 \mathrm{~m}$ long straight pipe is compressed into a $30 \mathrm{~cm}$ spiral.

At a pressure drop of 580 psi, the percentage of degradation found in both screws was about $8.5 \%$ in all the experiments. This represents a significant improvement and an acceptable performance since Husveg et al. (2019) reported a degradation of $10 \%$ at the same pressure drop (40 bar) and HPAM concentration (1000 ppm) in the design of a surface 


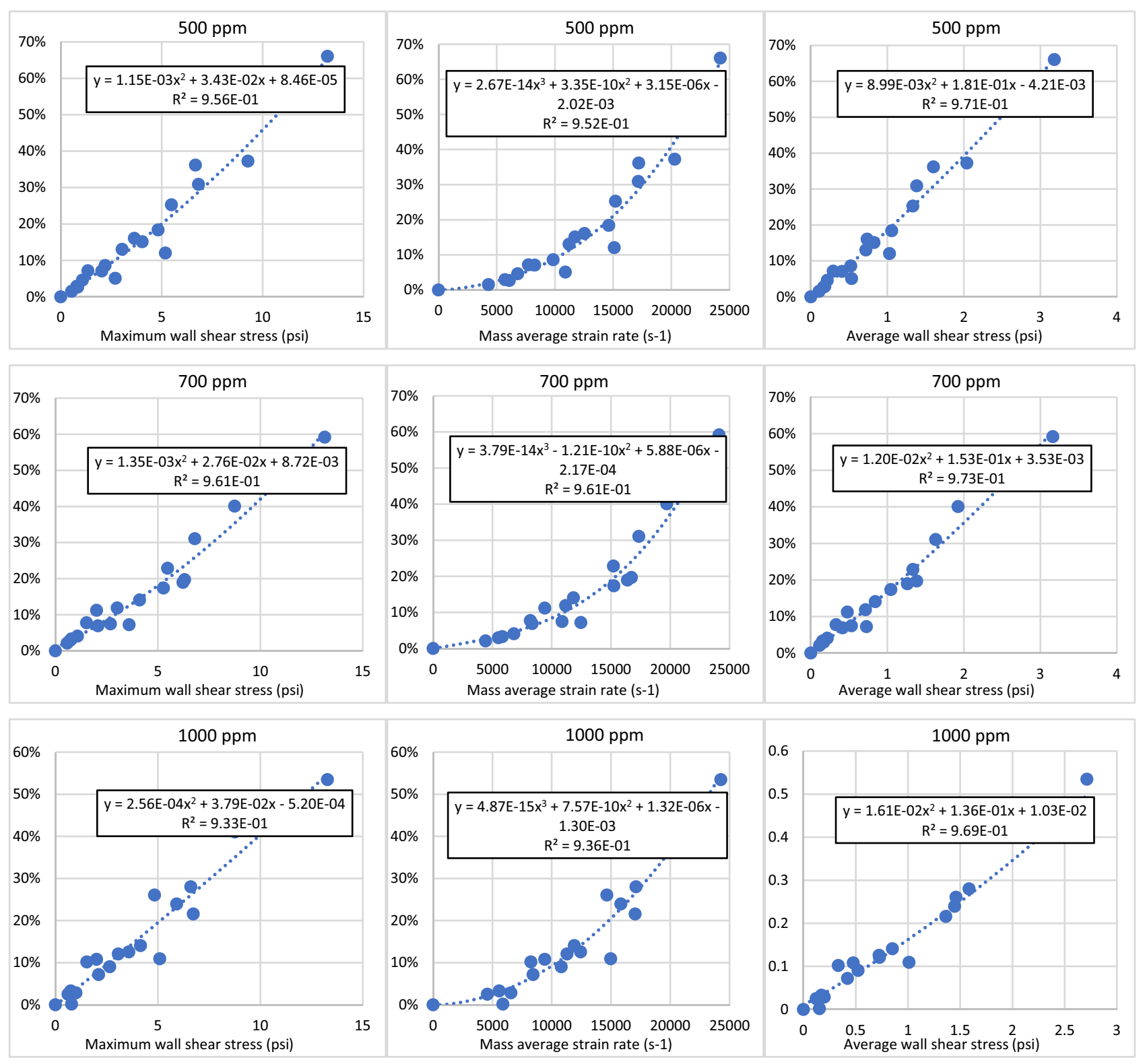

Fig. 11 Relation between the percentage of degradation and the strain rate/wall shear stress. In every graph, the $y$ axis (vertical) corresponds to the percentage of degradation. Variable $x$ in equations corresponds to the horizontal axis values

control valve for polymers. Nonetheless, the physico-chemical properties of the HPAM solutions are different in this work.

The pressure drop obtained with the CFD simulations when compared with the experimental data showed a satisfactory agreement with a percentage of deviation of about $4.5 \%$ and the rest of the simulation results were considered representative of the behavior of the fluid within the valve. The purpose of the simulation was to find a flow parameter that was independent of the size and type of restriction and that provided a suitable fit when correlated with the percentage of degradation obtained experimentally. The flow parameters that best correlated with the degradation obtained experimentally were the wall shear stress and the strain rate. The wall shear stress can be calculated as a maximum value or a as a surface area average. Both values were used. The strain rate can also be calculated on the walls, however, because it is a derivative of velocity in the normal direction to the wall (ANSYS 2019), it is dependent on the distance, and therefore, the size of the cell adjacent to it. Therefore, it is recommended to calculate a mass average value throughout the entire volume of the valve which is mesh size independent. When correlating the three parameters with the percentage of degradation, it was possible to 


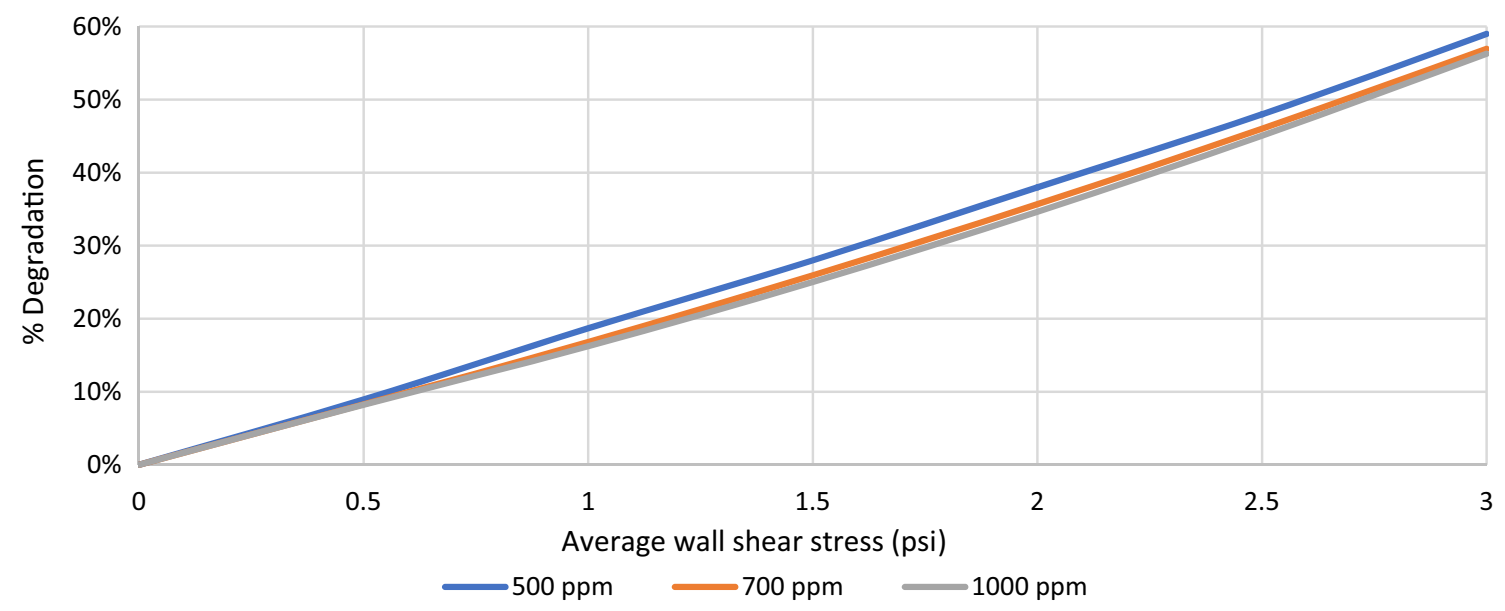

Fig. 12 Effect of the HPAM concentration in the percentage of degradation

find a better regression coefficient $\left(\mathrm{R}^{2}\right)$ with the average wall shear stress in all the cases with a value of about 0.97 (1 being a perfect fit). The average wall shear stress is probably the parameter that best represents the forces exerted on the fluid that create the scission of the polymer chains. A similar conclusion is presented by Stavland et al. (2016), these investigators analyzed the degradation of EOR polymers while flowing through capillary tubes and assured that degradation is not controlled by pressure, but by applied shear rate.

Figure 7 shows the wall shear stress in the $4.5-9 \mathrm{~mm}$ internals with a flow of 564 BPD of HPAM. It can be seen that the maximum value of the wall shear stress is right at the entrance of each reduction. This phenomenon is inevitable if reductions are to be used as flow restrictions. Figure 9 shows wall shear stress in the $3 \mathrm{~mm}$ wide $-4.5 \mathrm{~mm}$ depth channel-28 loop screw with flow of 563BPD of HPAM. It can be seen that the maximum value of the wall shear stress is at the entrance of the channels. This occurs because there is an abrupt reduction in the transversal area of flow and an abrupt change in the flow direction which can be improved with the design of a smooth reduction at the channel's entrance which would reduce the polymer degradation.

Figure 12 shows a slight dependence of the percentage of degradation with the concentration of HPAM in the solution. The effect of a higher HPAM concentration in the solution is an increase in the viscosity and it is taken into account in the calculation of the wall shear stress (ANSYS 2019). However, solutions with lower HPAM concentration (lower viscosity) generate a higher velocity adjacent to the walls which generates a higher wall strain rate and, therefore, higher degradation.

Some authors have correlated the degradation of the polymer with parameters such as pressure drop, velocity of flow or nozzle diameter (Jouenne et al. (2014), Bouts and Rijkeboer (2014), Gomez et al. (2018)). However, those parameters are dependent on the type of restriction which means that those correlations cannot be used to design new types of restrictions or devices to control the flow. Figure 13 presents the relation between the percentage of degradation and the pressure drop obtained in the all the experiments with all the restrictions. The data is divided in two groups: the results obtained with the reduction-expansion internals, and the results obtained with the screw internals. Each group individually follows similar tendencies and can be correlated with an acceptable regression coefficient. However, the results are very different if compared jointly. The geometry of the screw provides a much higher pressure drop and lower degradation at the same flowrate. In Fig. 11, one can see that, independent of the geometry of the restriction, the percentage of degradation can be correlated with the average wall shear stress with an adequate regression coefficient and can be used to design new types or new geometries for valves or any other control device.

A general correlation that includes the effect of the average wall shear stress and also the effect of the concentration of HPAM on the percentage of degradation [\% Deg] was developed and is presented in Eq. 7. Parameters A, B and C of the polynomial were correlated with the HPAM concentration (see Fig. 14) and a perfect fit was obtained for the three parameters (Eqs. 8, 9 and 10).

$\% \operatorname{Deg}=A \tau_{w}^{2}+B \tau_{w}+C$

where

$A=-2.8327 \cdot 10^{-9} \mathrm{ppm}^{2}+1.8402 \cdot 10^{-5} \mathrm{ppm}+4.9447 \cdot 10^{-4}$ 


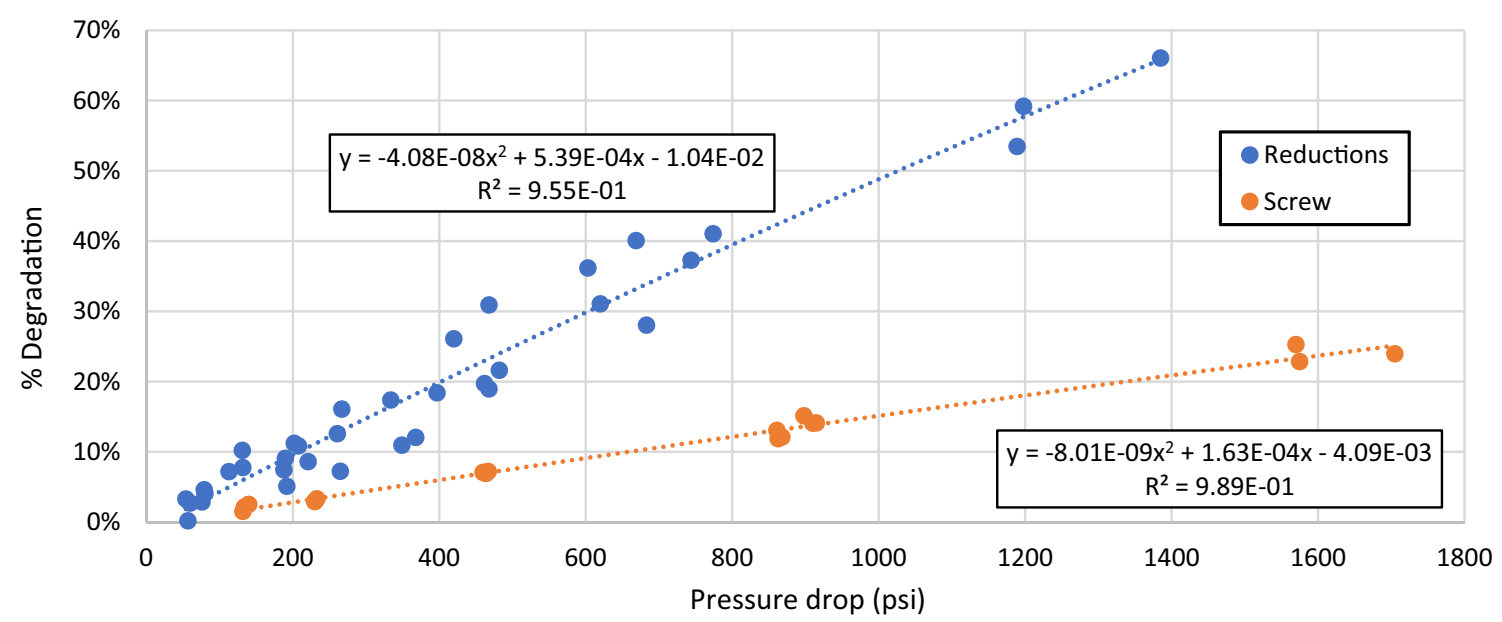

Fig. 13 Relation between the percentage of degradation and the pressure drop obtained experimentally
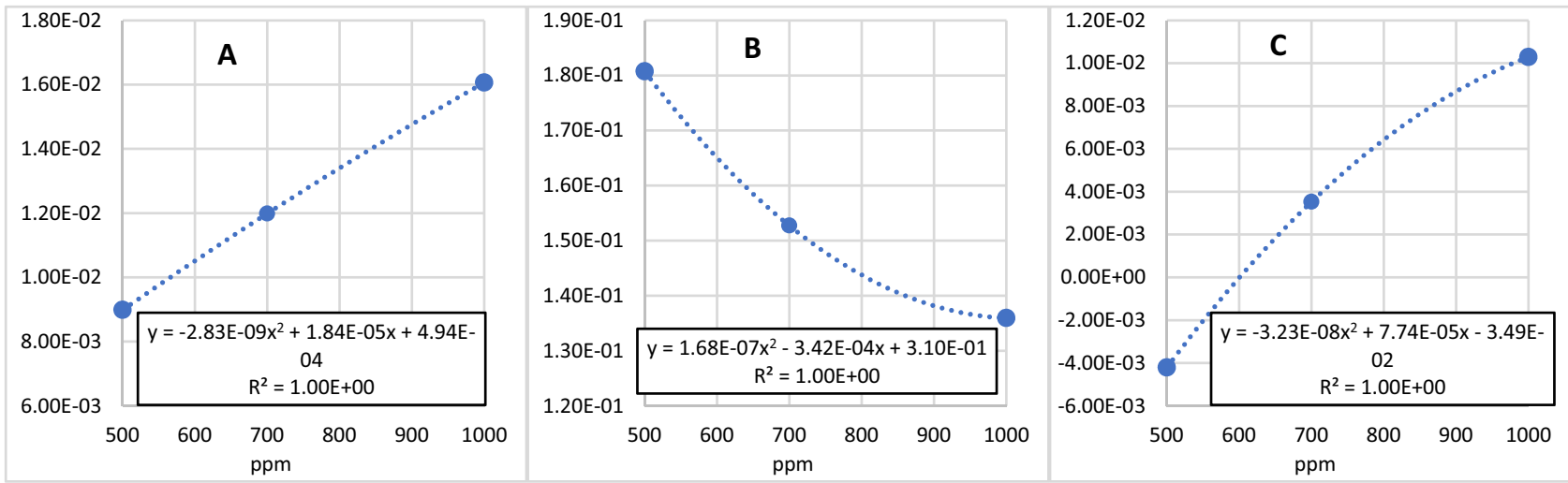

Fig. 14 Relation between the parameters $A, B$ and $C$ of Eq. 8 and the concentration of HPAM. Variable $x$ in equations corresponds to the horizontal axis values

$B=1.6813 \cdot 10^{-7} \mathrm{ppm}^{2}-3.4176 \cdot 10^{-4} \mathrm{ppm}+3.0959 \cdot 10^{-1}$

$C=-3.2293 \cdot 10^{-8} \mathrm{ppm}^{2}+7.7437 \cdot 10^{-5} \mathrm{ppm}-3.4852 \cdot 10^{-2}$

ppm, HPAM concentration [ppm], $\tau_{w}$ Average wall shear stress [psi].

\section{Conclusions}

The system of reduction-expansions of the polymer flooding regulator valve designed in this work presented an adequate performance for pressure drops lower than 300 psi with a percentage of degradation below $10 \%$. With that pressure drop the HPAM solutions can flow between 300 and 500 BPD for reductions of 4.5-6 $\mathrm{mm}$ in diameter.

In order to achieve a higher pressure drop and lower degradation of polymer in the valve, two screw-like pieces were designed. The screw can replace the reduction-expansions and be inserted into the central cylindrical piece to create dual spiral channels for the flow of polymer. With these internals, the flow of HPAM can be regulated up to 580 psi of pressure drop with a percentage of degradation below $8.5 \%$ and a flow between 300 and 500 BPD. Husveg et al. (2019) reported a degradation of $10 \%$ at the same pressure drop (40 bar) and HPAM concentration $(1000 \mathrm{ppm})$ with a flow of $480 \mathrm{BPD}$ in the design 
of a surface valve for polymers. These investigators also reported an HPAM degradation of $60 \%$ at the same conditions using a traditional choke valve for water injection.

CFD simulations were done with the purpose of developing a degradation model that could be used to design new types of valves and devices to control the flow of polymers. When the pressure drop obtained in the experiments was compared with the simulation results an average percentage of deviation of 4.5 was calculated and the simulations were considered representative of the behavior of the fluid within the valve. The results of the simulations were analyzed and compared to the percentage of degradation obtain experimentally. It was found that the average wall shear stress correlated with the experimental data at the highest regression coefficient. Results demonstrated that this parameter runs independently of the size and type of restriction in the valve, and best represented the forces exerted on the fluid that created the scission of the polymer chains.

The CFD simulations also permitted the observation of the wall shear stress on the valve. The highest values were found at the entrance of each reduction and at the entrance of the channels created by the screw. The wall shear stress is significantly higher at the first loop of the channels due to an abrupt reduction in the transversal area of flow and an abrupt change in the flow direction. With the design of a smooth reduction at the entrance of the channel, the wall shear stress can be reduced and therefore, polymer degradation can be reduced as well.

The performance of devices for polymer flooding EOR should not be analyzed by using variables such as pressure drop, flow velocity or nozzle diameter as suggested by other authors. Instead, it should be analyzed in terms of the average wall shear stress created by the flow of polymer in the device. Degradation is not controlled by velocity or pressure drop, but by applied wall shear stress. This research found that by using a value of the wall shear stress lower than 0.2 psi will degrade less than $3 \%$ the solution of polymer, regardless of the concentration or pressure drop. This can be achieved by avoiding abrupt changes in the area and the direction of flow and by the use of smooth flow restrictions unlike the ones used in water flow control.

If pressure drops above 300 psi are needed to control HPAM flow, the use of reductions or nozzles are probably not the best type of restrictions to be used in control devices. Instead, the use of spirals, channels, coils or similar designs is recommended. This research will continue with the design and optimization of multiple spiral channels for polymer flow control.

A correlation was developed to calculate the percentage of degradation from the average wall shear stress and the concentration of HPAM and it is presented on Eq. 8. It can be used to estimate the degradation in control devices with concentrations within 500-1000 ppm of HPAM. The expected error is in the range of $0-3 \%$ for the valve geometries used in this work.

Open Access This article is licensed under a Creative Commons Attribution 4.0 International License, which permits use, sharing, adaptation, distribution and reproduction in any medium or format, as long as you give appropriate credit to the original author(s) and the source, provide a link to the Creative Commons licence, and indicate if changes were made. The images or other third party material in this article are included in the article's Creative Commons licence, unless indicated otherwise in a credit line to the material. If material is not included in the article's Creative Commons licence and your intended use is not permitted by statutory regulation or exceeds the permitted use, you will need to obtain permission directly from the copyright holder. To view a copy of this licence, visit http://creativecommons.org/licenses/by/4.0/.

\section{Appendix}

See Table 3. 
Table 3 Complete set of experimental and simulation results

\begin{tabular}{|c|c|c|c|c|c|c|c|c|c|}
\hline $\begin{array}{l}\text { HPAM solu- } \\
\text { tion }\end{array}$ & Fitting & Flow (BPD) & $\Delta \mathrm{P}$ Simu (psi) & $\begin{array}{l}\text { Max wall } \\
\text { shear } \\
\text { stress }\end{array}$ & $\begin{array}{l}\text { Ave wall } \\
\text { shear } \\
\text { stress }\end{array}$ & Strain rate & $\Delta \mathrm{P}$ Expe (Psi) & $\begin{array}{l}\% \text { Deg- } \\
\text { radation } \\
(\%)\end{array}$ & $\%$ Deviation $(\%)$ \\
\hline \multirow[t]{18}{*}{ EOR 500} & \multirow[t]{3}{*}{$4.5-9 \mathrm{~mm}$} & 228.72 & 207.28 & 2.1967 & 0.5224 & 9852.12 & 221 & 8.59 & 6.2 \\
\hline & & 399.84 & 636.95 & 6.6766 & 1.6019 & $17,205.18$ & 603 & 36.16 & 5.6 \\
\hline & & 563.04 & 1267.02 & 13.2124 & 3.1825 & $24,211.77$ & 1385 & 66.03 & 8.5 \\
\hline & \multirow[t]{3}{*}{$5.0-9 \mathrm{~mm}$} & 212 & 106.4 & 1.3485 & 0.2921 & 7726.09 & 113 & 7.16 & 5.8 \\
\hline & & 402 & 386.18 & 4.8219 & 1.0558 & $14,628.92$ & 397 & 18.37 & $2.7 \%$ \\
\hline & & 558 & 746.76 & 9.2724 & 2.0388 & $20,291.07$ & 744 & 37.25 & 0.4 \\
\hline & \multirow[t]{3}{*}{$5.5-9 \mathrm{~mm}$} & 218.8 & 73.945 & 1.0769 & 0.2146 & 6805.25 & 79 & 4.59 & 6.4 \\
\hline & & 403.6 & 253.98 & 3.6441 & 0.7347 & $12,537.55$ & 267 & 16.07 & 4.9 \\
\hline & & 553 & 478.91 & 6.8274 & 1.3827 & $17,168.27$ & 468 & 30.90 & 2.3 \\
\hline & \multirow[t]{3}{*}{$6.0-9 \mathrm{~mm}$} & 225.6 & 54.82 & 0.8435 & 0.1645 & 6083.6 & 60 & 2.69 & 8.6 \\
\hline & & 404.64 & 178.18 & 2.6996 & 0.533 & $10,899.93$ & 192 & 5.09 & 7.2 \\
\hline & & 561.12 & 344.39 & 5.1813 & 1.028 & $15,106.37$ & 368 & 12.04 & 6.4 \\
\hline & \multirow{3}{*}{$\begin{array}{l}\text { Screw } \\
\quad 3 \mathrm{~mm}-28 \mathrm{~L}\end{array}$} & 212.69 & 221.84 & 0.7943 & 0.1827 & 5726.3 & 230 & 2.91 & 3.5 \\
\hline & & 404.58 & 858.41 & 3.0403 & 0.7191 & $11,223.94$ & 861 & 13.04 & 0.3 \\
\hline & & 541.55 & 1581.5 & 5.4839 & 1.3328 & $15,211.25$ & 1570 & 25.26 & 0.7 \\
\hline & \multirow{3}{*}{$\begin{array}{l}\text { Screw } \\
\quad 4 \mathrm{~mm}-24 \mathrm{~L}\end{array}$} & 212.69 & 120.88 & 0.5358 & 0.1068 & 4288.26 & 132 & 1.52 & 8.4 \\
\hline & & 399.84 & 449.43 & 2.0317 & 0.4064 & 8273.28 & 460 & 7.07 & 2.3 \\
\hline & & 558 & 901.45 & 4.0376 & 0.8256 & $11,725.28$ & 898 & 15.11 & 0.4 \\
\hline \multirow[t]{18}{*}{ EOR 700} & \multirow[t]{3}{*}{$4.5-9 \mathrm{~mm}$} & 218.64 & 189.22 & 2.008 & 0.4771 & 9415.43 & 202 & 11.20 & 6.3 \\
\hline & & 403.44 & 648.71 & 6.8048 & 1.6312 & $17,355.47$ & 620 & 31.05 & 4.6 \\
\hline & & 561.12 & 1258.58 & 13.1446 & 3.1618 & $24,125.03$ & 1198 & 59.17 & 5.1 \\
\hline & \multirow[t]{3}{*}{$5.0-9 \mathrm{~mm}$} & 225 & 119.92 & 1.5183 & 0.3292 & 8198.86 & 132 & 7.74 & 9.2 \\
\hline & & 460 & 506.37 & 6.3085 & 1.3838 & $16,734.16$ & 462 & 19.69 & 9.6 \\
\hline & & 542 & 704.29 & 8.7483 & 1.9231 & $19,710.49$ & 669 & 40.07 & 5.3 \\
\hline & \multirow[t]{3}{*}{$5.5-9 \mathrm{~mm}$} & 218.96 & 74 & 1.0784 & 0.2149 & 6810.37 & 80 & 4.06 & 7.5 \\
\hline & & 401.1 & 250.91 & 3.5988 & 0.7255 & $12,460.2$ & 265 & 7.21 & 5.3 \\
\hline & & 528.11 & 436.55 & 6.2272 & 1.2606 & $16,397.04$ & 468 & 18.94 & 6.7 \\
\hline & \multirow[t]{3}{*}{$6.0-9 \mathrm{~mm}$} & 216 & 50.26 & 0.7751 & 0.151 & 5831.39 & 54 & 3.27 & 6.9 \\
\hline & & 403.68 & 177.38 & 2.6864 & 0.5304 & $10,874.34$ & 188 & 7.44 & 5.6 \\
\hline & & 566.16 & 350.67 & 5.2742 & 1.0466 & 15,242 & 334 & 17.37 & 5.0 \\
\hline & \multirow{3}{*}{$\begin{array}{l}\text { Screw } \\
\quad 3 \mathrm{~mm}-28 \mathrm{~L}\end{array}$} & 204.85 & 205.09 & 0.7324 & 0.1687 & 5506.73 & 230 & 2.96 & 10.8 \\
\hline & & 402.96 & 851.25 & 3.0115 & 0.713 & $11,178.47$ & 863 & 11.85 & 1.4 \\
\hline & & 541.55 & 1581.29 & 5.4773 & 1.3328 & $15,212.43$ & 1575 & 22.84 & 0.4 \\
\hline & \multirow{3}{*}{$\begin{array}{l}\text { Screw } \\
\quad 4 \mathrm{~mm}-24 \mathrm{~L}\end{array}$} & 219 & 128.33 & 0.571 & 0.1135 & 4418.84 & 134 & 2.10 & 4.2 \\
\hline & & 403.6 & 458.1 & 2.0744 & 0.4146 & 8354.99 & 464 & 6.89 & 1.3 \\
\hline & & 563 & 918.22 & 4.1051 & 0.8415 & $11,835.8$ & 910 & 14.06 & 0.9 \\
\hline \multirow[t]{12}{*}{ EOR 1000} & \multirow[t]{3}{*}{$4.5-9 \mathrm{~mm}$} & 218.64 & 189.33 & 2.0073 & 0.4772 & 9414.21 & 208 & 10.82 & 9.0 \\
\hline & & 397.68 & 630.26 & 6.605 & 1.5845 & $17,108.53$ & 683 & 28.02 & 7.7 \\
\hline & & 564.48 & 1273.35 & 13.281 & 2.7125 & $24,270.21$ & 1189 & 53.47 & 7.1 \\
\hline & \multirow[t]{3}{*}{$5.0-9 \mathrm{~mm}$} & 226.3 & 121.48 & 1.5352 & 0.3332 & 8245.54 & 131 & 10.19 & 7.3 \\
\hline & & 402.7 & 387.7 & 4.8395 & 1.4597 & $14,653.74$ & 420 & 26.06 & 7.7 \\
\hline & & 542.4 & 705.45 & 8.7627 & 2.5261 & $19,723.98$ & 774 & 41.03 & 8.9 \\
\hline & \multirow[t]{3}{*}{$5.5-9 \mathrm{~mm}$} & 211.07 & 68.83 & 1.0022 & 0.1998 & 6564.26 & 76 & 2.85 & 9.4 \\
\hline & & 400.42 & 250.17 & 3.5871 & 0.7233 & $12,438.05$ & 261 & 12.57 & 4.1 \\
\hline & & 548.92 & 471.89 & 6.7277 & 1.3625 & $17,041.13$ & 482 & 21.58 & 2.1 \\
\hline & \multirow[t]{3}{*}{$6.0-9 \mathrm{~mm}$} & 218 & 50.99 & 0.787 & 0.1531 & 5877.56 & 57 & 0.17 & 10.5 \\
\hline & & 401.04 & 174.98 & 2.6514 & 0.5232 & $10,804.29$ & 190 & 9.05 & 7.9 \\
\hline & & 556.32 & 338.22 & 5.0917 & 1.0102 & $14,978.27$ & 349 & 10.93 & 3.1 \\
\hline
\end{tabular}


Table 3 (continued)

\begin{tabular}{|c|c|c|c|c|c|c|c|c|c|}
\hline $\begin{array}{l}\text { HPAM solu- } \\
\text { tion }\end{array}$ & Fitting & Flow (BPD) & $\Delta \mathrm{P}$ Simu (psi) & $\begin{array}{l}\text { Max wall } \\
\text { shear } \\
\text { stress }\end{array}$ & $\begin{array}{l}\text { Ave wall } \\
\text { shear } \\
\text { stress }\end{array}$ & Strain rate & $\Delta \mathrm{P}$ Expe (Psi) & $\begin{array}{l}\% \text { Deg- } \\
\text { radation } \\
(\%)\end{array}$ & $\%$ Deviation $(\%)$ \\
\hline & \multirow{3}{*}{$\begin{array}{l}\text { Screw } \\
\quad 3 \mathrm{~mm}-28 \mathrm{~L}\end{array}$} & 206.97 & 209.45 & 0.7478 & 0.1724 & 5566.07 & 233 & 3.29 & 10.1 \\
\hline & & 406.94 & 868.88 & 3.0707 & 0.7279 & $11,295.17$ & 868 & 12.09 & 0.1 \\
\hline & & 563.04 & 1714.41 & 5.9168 & 1.4462 & $15,839.18$ & 1705 & 23.95 & 0.6 \\
\hline & \multirow{3}{*}{$\begin{array}{l}\text { Screw } \\
\quad 4 \mathrm{~mm}-24 \mathrm{~L}\end{array}$} & 226.3 & 137.34 & 0.6106 & 0.1216 & 4572.85 & 140 & 2.51 & 1.9 \\
\hline & & 407 & 465.96 & 2.1059 & 0.4218 & 8429.18 & 467 & 7.20 & 0.2 \\
\hline & & 566 & 928.79 & 4.1545 & 0.8513 & $11,905.85$ & 915 & 14.08 & 1.5 \\
\hline
\end{tabular}

\section{References}

Al Hashmi AR, Al Maamari RS, Al Shabibi IS, Mansoor AM, Zaitoun A, Al Sharji HH (2013) Rheology and mechanical degradation of high-molecular-weight partially hydrolyzed polyacrylamide during flow through capillaries. J Pet Sci Technol Eng 105:100-106

ANSYS 2019 R2 user manual (2019), ANSYS Inc

Bouts MN, Rijkeboer MM (2014) Design of horizontal polymer injectors requiring conformance and sand control. SPE EOR OGWA, Muscat, Oman. SPE 169722-MS

Castro R, Maya G, Mercado D, Trujillo M, Soto C, Pérez H, Lobo A, Ordóñez A, Sandoval JE (2010) Enhanced oil recovery (EOR) status-Colombia. SPE LACPEC, Lima, Peru. SPE 139199

Castro-García RH, Maya-Toro GA, Jimenez-Diaz R, QuinteroPerez HI, Díaz-Guardia VM, Colmenares-Vargas KM, PalmaBustamante JM, Delgadillo-Aya CL, Pérez-Romero RA (2016) Polymer flooding to improve volumetric sweep efficiency in waterflooding processes. CT\&F-Ciencia, Tecnología y Futuro 6(3):71-90

Gomez JL, Gutierrez M, Herrera JJ, Quintero H, Castro RH, Jimenez R, Rueda MF (2018) Study of shear degradation on polymer solutions by geometry restrictions in turbulent flow via CFD. In: ANSYS convergence regional conferences, Bogota, Colombia

Husveg T, Stokka M, Jouenne S, Husveg R (2019) The development of a low shear valve suitable for polymer flooding. In: IOR 2019-20th European symposium on improved oil recovery. Pau, France

Jouenne S, Anfray J, Cordelier PR, Mateen K, Levitt D, Souilem I, Marchal P, Choplin L, Nesvik J, Waldman TE (2014) Degradation (or Lack Thereof) and drag reduction of HPAM during transport in pipelines. SPE EOR OGWA, Muscat, Oman. SPE-169699-MS

Jouenne S, Chakibi H, Levitt D (2017) Polymer stability after successive mechanical-degradation events. SPE J 23(01). SPE-186103-PA

Perez R, Castro Garcia RH, Jimenez R, Maya GA, Leon Hinestrosa JM, Reyes JD, Mendez A, Castillo Mejia AF, Romero MP, Fernandez Bedoya F, Quintero Roa LM, Quintero H (2017) Mature field revitalization using polymer flooding: palogrande-Cebú Field Case. SPE LACPEC, Buenos Aires, Argentina. SPE-185552-MS
Perkins TT, Smith DE, Chu S (1997) Single polymer dynamics in an elongational flow. Science 276:2016-2021

Rellegadla S, Ganshyam P, Akhil A (2017) Polymers for enhanced oil recovery: fundamentals and selection criteria. Appl Microbiol Biotechnol 101(11):4387-4402

Seright RS (2017) How much polymer should be injected during a polymer flood? Review of previous and current practices. SPE J 22(1). SPE-179543-PA

Sheng J (2013) Enhanced oil recovery field case studies. Gulf Professional Publishing, Waltham

Stavland A, Jonsbraten HC, Lohne A, Moen A, Giske NH (2010) Polymer flooding-flow properties in porous media versus rheological parameters. In: SPE EUROPEC/EAGE Annual conference and exhibition, Barcelona, Spain. SPE 131103

Stavland A, Asen S, Mebratu A, Gathier F (2016) Impact of choke valves on the IOR polymer flooding Lessons learned from large scale tests. In: IEA-EOR 2016 - 37th annual workshop \& symposium, Rueil-Malmaison

Strickland PH, Wilson JT, Warnock WE (1978) The feasibility of converting an existing waterflood into a polymer flood: a case history of west yellow creek. In: 53rd annual fall technical conference and exhibition, Houston, Texas, USA. SPE 7462

Wang D, Seright RS, Shao Z, Wang J (2008) Key aspects of project design for polymer flooding at the Daqing oil field. SPE Reservoir Evaluation and Engineering. SPE 109682

Xiong B, Loss RD, Shields D, Pawlik T, Hochreiter R, Zydney AL, Kumar M (2018) Polyacrylamide degradation and its implications in environmental systems. NPJ Clean Water 1(17)

Yasuda K (1979) Investigation of the analogies between viscometric and linear viscoelastic properties of polystyrene fluids. Ph.D. thesis dissertation, Dept. of Chemical Engineering, Massachusetts Institute of Technology

Zerkalov G (2015) Polymer Flooding for Enhanced Oil Recovery, Submitted as coursework for PH240, Stanford University

Publisher's Note Springer Nature remains neutral with regard to jurisdictional claims in published maps and institutional affiliations. 